\title{
Physicians' medication prescribing in primary care in Riyadh city, Saudi Arabia. Literature review, part 1: variations in drug prescribing
}

Y. Neyaz, ${ }^{1}$ N.A. Qureshi, ${ }^{2}$ T. Khoja, ${ }^{3}$ M.A. Magzoub, ${ }^{4}$ A. Haycox ${ }^{5}$ and T. Walley ${ }^{6}$

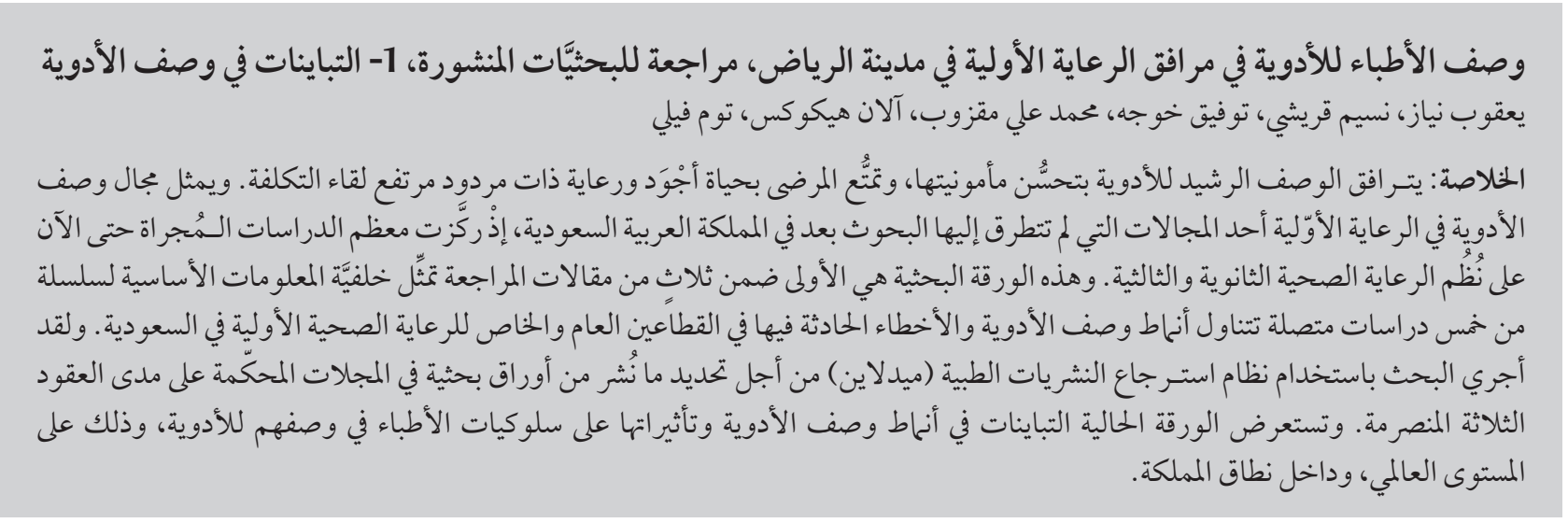

ABSTRACT Rational prescribing is associated with improved safety in drug use, better quality of life for patients and cost-effective care. Medication prescribing is a relatively unexplored area of research in Saudi Arabia and until now most studies have been in the secondary and tertiary health care system. This paper is the first of 3 review articles that form the background for a series of 5 interconnected studies of prescribing patterns and medication errors in the public and private primary health care sectors of Saudi Arabia. A MEDLINE search was conducted to identify papers published in peer-reviewed journals over the previous 3 decades. The paper reviews variations in prescribing patterns and influences on physicians' prescribing behaviour worldwide and in Saudi Arabia.

Comportement prescripteur des médecins en soins de santé primaires à Riyadh (Arabie saoudite). Examen des publications, première partie : variations dans la prescription de médicament

RÉSUMÉ La prescription rationnelle est associée à une plus grande sécurité de l'utilisation des médicaments, à une meilleure qualité de vie des patients et au rapport coût-efficacité des soins. La prescription de médicaments est un domaine de la recherche relativement peu étudié en Arabie saoudite et, jusqu'à présent, la plupart des études ont été réalisées dans le système de soins de santé secondaires et tertiaires. Le présent article est le premier de trois articles de synthèse qui constituent le contexte de recherche d'une série de cinq études interdépendantes sur les modes de prescription et les erreurs de médication dans les secteurs public et privé des soins de santé primaires en Arabie saoudite. Une recherche sur MEDLINE a été réalisée pour identifier les travaux publiés dans des revues pratiquant l'examen collégial au cours des trente dernières années. Le présent article analyse les variations dans les modes de prescription et les facteurs influençant le comportement prescripteur des médecins dans le monde et en Arabie saoudite.

${ }^{1}$ General Directorate for Quality Development; ${ }^{2}$ General Administration for Mental Health and Social Services and Medical Research, Ministry of Health, Riyadh, Saudi Arabia (Correspondence to N.A. Qureshi: qureshinaseem@live.com).

${ }^{3}$ Cooperation Council for the Arab States of the Gulf, Riyadh, Saudi Arabia.

${ }^{4}$ Department of Medical Education, College of Medicine, King Abdulaziz Medical City, Riyadh, Saudi Arabia.

${ }^{5}$ School of Management; ${ }^{6}$ Department of Internal Medicine, University of Liverpool, Liverpool, United Kingdom. 


\section{Introduction}

Medication prescribing is a relatively unexplored area of research in Saudi Arabia and until now most studies of physicians' prescribing have been in the secondary and tertiary health care system. However, the great majority of health care consultations, and hence drug prescriptions, occur in the primary health care (PHC) system, both private and public. Hence medication errors at the PHC level are likely to be more clinically significant. Such errors may be hidden, given that their incidence, aetiologies and consequences have not been fully explored. The extent of this hidden health problem is greater in rapidly developing countries than in developed countries, in which systems for their detection are better established.

Throughout the world prescribing is one of most important functions of a physician. Physicians working in PHC are faced with a high volume of patients, who are presenting, often for the first time, with a wide range of physical as well as psychological symptoms. In addition, PHC physicians usually have limitations on their facilities for investigations and the time available to reach a diagnosis. The physician is under pressure to reach a diagnosis and initiate a patient management programme which almost invariably involves medication. The reasons for prescribing may be numerous. A drug may be prescribed in response to a presumed diagnosis or symptoms, or as a placebo to relieve patient anxiety, or simply as the easiest way to terminate the consultation [1]. The pressure to prescribe is strong not only in rapidly developing countries such as Saudi Arabia but internationally [2-5]. Consultations often result in the prescription of multiple drugs and the causes of this have also been analysed nationally and internationally [2,4-9]. Sometimes polypharmacy is entirely justified, for example in the management of cardiovascular problems. Often, however, polypharmacy simply represents a knee-jerk response to the complexity and range of symptoms which a patient may present. Polypharmacy may also result from patient expectations that equate more prescriptions with better medicine.

Increasing the number of items per prescription increases the possibilities for errors and interactions. A study undertaken in Saudi Arabia revealed that about $12 \%$ of prescriptions in PHC settings have one or more prescribing errors which range from the trivial to the potentially life-threatening [5]. The practice of inappropriate polypharmacy [10] and other aspects of suboptimal prescribing also contribute to huge increases in the drugs bill $[3,11]$, an issue which is a great concern to health and financial authorities globally $[12,13]$.

The factors influencing prescribing patterns can be divided into 3 broad groups: physician factors, such as their clinical skills, experience, education and training; patient factors, that include their illness and past experiences; and external factors, such as social perceptions of illness and the availability of information (or lack of it) to doctors and the public about drugs [4,14-19].

A wide range of studies have highlighted concerns about inappropriate prescribing [20]. In Saudi Arabia, a range of initiatives have been developed aimed at improving both prescribing practice [5] and education for physicians and patients [4]. Nevertheless, there has been no sustained and coordinated approach to improving prescribing practices in Saudi Arabia. The available evidence emphasizes the challenges faced by Saudi Arabia in improving prescribing and reducing medication errors. Only by a coordinated analysis of the source of such problems will it be possible to delineate the factors associated with inappropriate prescribing. It will then be possible to develop clinical and costeffective interventions to enhance the quality of prescribing in Saudi Arabia. This paper is the first of 3 review articles that form the background for a series of
5 interconnected studies of prescribing patterns and medication errors in the public and private primary health care sectors of Saudi Arabia [21-25].

\section{Literature review: methods}

The starting point for delineating the determinants of prescribing behaviour and how it can be improved was to undertake a systematic review of the relevant literature. This paper and the two accompanying papers $[26,27]$ review three broad areas: first, what is already known about prescribing in the Gulf States; secondly, the evidence about variations in prescribing and influences on prescribing; and thirdly, issues relating to adverse drug reactions and prescribing errors. The authors acknowledge that there is an extensive literature from the United States (US), but it was felt that the elements of the structure and functioning of the Saudi Arabian health systems, in particular the publicly-funded sector, were more comparable with those of the United Kingdom (UK). For this reason, a systematic review of the US literature was not deemed appropriate in relation to influences on prescribing, but was conducted to cover the topic of medication errors.

The MEDLINE database was searched up to August 2005 to identify case reports, empirical studies, updates and review articles, meta-analyses, randomized double-blind clinical trials and panel workshops and discussions and drug use guidelines that involved rational drug prescribing, prescribing errors, and their prevention at several health care delivery levels. First, the term "prescribing" was used as a qualifier and combined with "rational", "errors", "adverse drug events", "good quality", "cost containment", "health reforms", "primary health care", "hospitals", "private health sector", "general practitioners", "PHC physicians", "consultants", "pharmacists", and "nurses". A second search 
used the term "medication or drugs" as a qualifier and combined with "patient safety", "prescription errors", "litigation", and "error prevention". All published citations were also cross-referenced for other relevant studies. In addition we undertook manual exploration of references within the co-authors' personal files to locate all research on medication prescribing or errors in Saudi Arabia and other Gulf states. All identified studies were critically reviewed.

\section{International variations} in drug prescribing

Prescribing patterns all levels of health care are characterized worldwide by large variations in prescribing rates, whether by volume, cost, therapeutic group or individual drug. Although there is no clear framework for identifying underlying reasons for differences in prescribing rates, variations have be attributed to patient-driven factors; administrative regulations; the evidence base for a drug's effectiveness; the absence of uniform guidelines; and the promotion of drugs by the pharmaceutical industry [28-30].

In Europe, for instance, French physicians traditionally prescribe high rates of benzodiazepines, as demonstrated in a community survey of a network of pharmacies [31]. The reasons for these differences seem to lie in variations in patients' demands for inappropriate drugs and possibly physicians' beliefs in the efficacy of drugs, and the acceptability of prescribing drugs as placebos [10]. There are also diagnostic differences across nations, with conditions such as liver disease apparently more prevalent in France or hypotension more prevalent in Germany, regardless of the true epidemiology or even pathological significance. In addition, some countries adopt new drugs faster than others; for instance the uptake of new drugs in the UK is slower than in other European countries, although this trend may be changing [32]. But even in markets that adopt new drugs more readily, old favourites of dubious clinical value can persist, for instance the continued use in Germany of fixed ratio combinations of reserpine and diuretics, even though such products have disappeared from use in the UK and Sweden [33]. There are also major differences in Europe in the prescription of cardiac glycosides [34] and thiazides [35]. UK doctors appear to be much less affected by medical representatives' promotion about new products, perhaps reflected in their therapeutic conservatism and slower uptake of new drugs [36]. UK general practitioners (GPs) tend to select established first-line drugs rather than second-line or less effective drugs.

There has been particular attention paid to the use of antibiotics, in part arising from concerns about the risk of development of antibiotic resistant strains of bacteria. Cars et al. described widespread variations in antibiotic use across the European Union, based on returns from IMS, a commercial company which tracks medication use and supplies information to the pharmaceutical industry [37]. The highest user was France, with 36 defined daily doses (DDD)/1000 patients/day and the lowest was the Netherlands with 8.8 DDDs/1000/day, a 4-fold difference. More recently, the European Surveillance of Antimicrobial Consumption project updated this work and extended it to 26 European countries, confirming these patterns [28]. Most importantly, they found new evidence that there were higher rates of bacterial resistance to commonly used antibiotics in highconsuming countries, for example in southern and eastern European countries, compared with the more restrained northern European countries.

Another area of interest is prescribing of lipid-lowering drugs. Variations in the use of statins have been reported by Walley et al., although a clear northsouth divide in Europe was not seen: Norway was the highest user, followed by France, with Italy the lowest; no correlation was found, however, with cardiovascular morbidity and mortality patterns [38]. The prescribing of statins also exemplifies the possible effects of changes in drug company promotions of particular drugs. When the patent for pravastatin expired, its use in Ireland declined in favour of drugs such as atorvastatin, probably due changes in promotional activities by the manufacturers of the 2 drugs [39].

It is important not to overplay the value of international comparisons, however. First, these are beset with methodological difficulties, because researchers may have used national prescribing data that may differ from the sampling approach adopted by IMS $[28,38,40]$ and used by Cars et al. [37]. Walley et al. have explored this by comparing IMS data to registry data and noted that each have their strengths and weaknesses, even within individual countries [40]. Secondly, although comparisons can be useful for benchmarking, each health care system requires a detailed examination ofits own strengths and weaknesses, since the aim is ultimately to improve quality within that system [41].

\section{Variation within countries and among doctors}

Prescribing not only varies between countries, but also within countries. This has been extensively studied as it can give clues to the factors which determine the propensity to prescribe and because policy-makers are interested in how variability in prescribing identifies both wasteful and harmful prescribing. There are many examples published over the past 15 years, some simply documenting variations in prescribing rates and other more useful studies relating variations in prescribing to observed levels of morbidity. The evidence discussed here is confined to selected studies in the UK. 
McGavock analysed prescribing data to compare differences in patterns of prescribing between GPs in 23 low-cost urban practices with 23 high-cost urban practices [42]. Patients in practices with high costs were given double the quantity of sleeping pills, 50\% more analgesics, antirheumatics, vitamins, cough medicines and laxatives and $40 \%$ more antacids than patients in the practices with low costs. Although underlying morbidity was not assessed, this variation owed more to the doctorpatient interaction than to morbidity.

Majeed et al. in the UK demonstrated a decline in antibiotic prescribing related to the fall in new diagnoses of respiratory tract infections (RTI) $[43,44]$. However, it is uncertain whether any real change in the incidence of minor RTI actually occurred and doctors may have altered their diagnosis to reflect their growing reluctance to prescribe antibiotics [45]. Both Majeed et al. and Unsworth and Walley noted that the decline in antibiotic use was less marked in areas with higher levels of deprivation. While this may be due to real difference in morbidity rates, Unsworth also speculated that this was due to both doctors' and patients' expectation $[44,45]$.

Majeed et al. have also demonstrated that statins were more likely to be prescribed in areas of higher socioeconomic class even thoughthese were notthe areas of highest morbidity [44]. Examination of the data over several years, however, showed that this trend was decreasing in response to government efforts and incentives to increase the use of drugs to prevent cardiovascular disease. Other factors which may explain differences in prescribing among doctors include responsiveness to financial incentives; the level of education of the GP; whether the GP practised single-handed or in a group [46]; the ethnicity of the doctor and the patient [47]; the behaviour of other doctors including hospital colleagues [48]; and susceptibility to promotional efforts by the pharmaceutical industry [49].
The most important influence on the choice of drug seems to be the relationship between the doctor and the patient; other factors may influence the more important decision whether to prescribe at all in many discretionary situations.

\section{Studies of drug use in Saudi Arabia and elsewhere in the Gulf states}

While the data on variations in or influences on prescribing in Saudi Arabia are very limited, many of the factors described earlier are likely to apply. The medical system of the country has some particular features, however, that might cause variations between doctors: many PHC physicians are not Saudi citizens; there is little formal postgraduate education; the pharmaceutical industry is active; and doctors in publicly-funded PHC centres are constrained by a very limited essential drugs formulary defined by the Ministry of Health $(\mathrm{MOH})$, whereas private doctors are not subject to formulary constraints.

Only a limited number of studies have explored the prescribing habits of physicians in different health care settings in Saudi Arabia, covering both non-psychiatric $[2,4-6,50-54]$ and psychotropic drugs $[55,56]$. In a study in a PHC setting, Khoja et al. examined 4 types of prescribing errors and found that relief of symptoms was the major reason for prescribing [5]. The number of drug items per prescription was 3.2, which were lower than in other studies in Saudi Arabia $[2,4,6]$, probably due to the study sampling and methods. In contrast, Al-Nasser, also in Saudi Arabia, reported a higher number of drugs per prescription dispensed to clients [2].

Elsewhere in the Eastern Mediterranean Region, in Bahrain, Al Khaja et al. explored 3 types of prescribing errors and also offered some recommendations, including improving prescribing skills [57]. In the Islamic Republic of
Iran, Moghadamnia et al. found overprescribing of drugs by general physicians [58]. In Jordan, Otoom et al. found over-prescribing of antibiotics and under-prescribing of generic drugs [59].

All the above authors made specific recommendations to improve the overall quality of prescribing in PHC. In a study of patients' self-medication that substantiated other studies $[51,60]$, Bawazir in Saudi Arabia reported that analgesics/antipyretics and dermatological drugs were the most commonly dispensed over-the-counter (OTC) drugs, while antibiotics were the most common drugs dispensed on prescription [6]. Other findings were that physicians commonly practised polypharmacy and that prescribing patterns were similar in hospital outpatient clinics and in PHC [6]. There were several specific recommendations from that study including enforcing the regulations governing the sale of drugs and the specifications of drugs that are allowed to be sold OTC.

Al-Faris and Al-Taweel found that the most frequently prescribed drugs in Saudi Arabia were antihistamines (25\%), paracetamol (20\%) and antibiotics (15\%) [61]. In over 50\% of prescriptions, the diagnosis was upper RTI for which antibiotics (26\%) and antihistamines (28\%) were the usual treatments. The need for education of both patients and doctors regarding the benefits of treatment was emphasized.

Key points to note from the above studies in the Gulf and Saudi Arabia are:

- There is inadequate data on prescribing in the Gulf region.

- Prescription of drugs is one of the most important factors in the rising costs of health services in the region.

- Most consultations at all health delivery levels end with a drug prescription.

- There is a need for continuing education of doctors and pharmacists about cost-effective and appropriate drugs for prescribing and for patients' self-medication. 
- There is a need for patient education on the benefits of drug treatments and control of chronic diseases.

- Further studies of the prescribing habits of professionals, coupled with critical feedback, are needed to improve the quality of prescribing at all health levels.
- Short, intensive courses on mental health disorders are needed to enhance physicians' skills in identifying and rationally prescribing psychotropic drugs for patients with mental disorders.

- There is a need for future studies assessing different aspects of pre- scribing errors, clinical as well as nonclinical.

To summarize, medication prescribing patterns vary nationally and internationally for multiple reasons and these patterns reciprocally influence the behaviours of consumers and prescribers.

\section{References}

1. Bradley CP. Decision making and prescribing patterns-a literature review. Family Practice, 1991, 8:276-287.

2. Al-Nasser AN. Prescribing patterns in primary health care in Saudi Arabia. Annals of Pharmacotherapy, 1991, 25:90-93.

3. Gilleghan J. Prescribing in general practice. Occasional Papers London: Royal College of General Practice, 1991; 54:18-35.

4. Felimban FM. The prescribing practice of primary health care physicians in Riyadh city. Saudi Medical Journal, 1993, 14:335-338.

5. Khoja TA et al. Quality of prescribing at primary care centres in Saudi Arabia. Journal of Pharmacy Technology, 1996, 12:284-288.

6. Bawazir S. Prescribing patterns of ambulatory care physicians in Saudi Arabia. Annals of Saudi Medicine, 1993, 13:172-177.

7. Hogerzeil $\mathrm{H}$ et al. Impact of an essential drug program on availability and rational use of drugs. Lancet, 1989, 333:141-142.

8. Dizwani A et al. Morbidity patterns and prescribing habit in Harare primary care clinics. Family Practice, 1985, 2:82-85.

9. Krishnaswamy K, Dinesh K, Radhaiah R. A drug survey-percepts and practices. European Journal of Clinical Pharmacology, 1985, 29:363-370.

10. Schwartz RK, Soumerai SB, Avorn J. Physician motivations for non-scientific prescribing. Social Science and Medicine, 1989, 28:577-582.

11. Annual health report. Riyadh, Saudi Arabia, Ministry of Health, 1999.

12. Taylor D. Prescribing in Europe-forces for change. British Medical Journal, 1992, 304:239-242.

13. Wilkie $\mathbf{P}$ et al. Prescribing at the hospital general practice interface. In: Hospital outpatient dispensing policies in England. British Medical Journal, 1992, 304:29-31.

14. Hemminki E. Review of literature on the factors affecting drugs prescribing. Social Science and Medicine, 1975, 9:111-115.

15. Renieri A, Piperno A. Factors affecting list size of general practitioners and number of drugs prescribed: findings of a recent study. Social Science and Medicine, 1983, 17:335-341.

16. Al-Abbasi H. Drug utilization study: Prescription patterns and patient level of comprehension in Jeddah, Saudi Arabia [Doctor of Public Health thesis]. Department of Public Health, Tulane University, New Orleans, USA, 1986.

17. Soumerai SB, Lipton HL. Evaluating and improving physician prescribing. In: Strom BL, ed. Pharmacoepidemiology, 2nd ed. New York, John Wiley, 1994.

18. Raisch D. A model of methods for influencing: Part 1. A review of prescribing models, persuasion theories, and administrative and education methods. DICP: the Annals of Pharmacotherapy, 1990, 24:417-421.

19. Tabbara K, Frayha H. The use and abuse of antibiotics. Annals of Saudi Medicine, 1996, 16:495-496.
20. Sandars J, Esmail A. The frequency and nature of medical error in primary care: understanding the diversity across studies. Family Practice, 2003, 20:231-236.

21. Neyaz $\mathrm{Y}$ et al. Medication prescribing pattern in primary care in Riyadh city, Saudi Arabia. Eastern Mediterranean Health Journal, 2011, 17(2):149-155.

22. Khoja $\mathrm{T}$ et al. Medication errors in primary care in Riyadh city, Saudi Arabia. Eastern Mediterranean Health Journal, 2011, 17(2):156-169.

23. Magzoub MA et al. Determinants of physicians' medication prescribing behaviour in primary care in Riyadh city, Saudi Arabia. Eastern Mediterranean Health Journal, 2011, 17(2):160-166.

24. Neyaz $\mathrm{Y}$ et al. Predictors of quality of medication prescribing in primary care in Riyadh city, Saudi Arabia. Eastern Mediterranean Health Journal, 2011, 17(2):167-171.

25. Qureshi NA et al. Effectiveness of three interventions on primary care physicians' medication prescribing in Riyadh city, Saudi Arabia. Eastern Mediterranean Health Journal, 2011, 17(2):172-179.

26. Khoja T et al. Physicians' medication prescribing in primary care in Riyadh city, Saudi Arabia. Literature review, part 2: rational prescribing. Eastern Mediterranean Health Journal, 2011, 17132-139.

27. Qureshi NA et al. Physicians' medication prescribing in primary care in Riyadh city, Saudi Arabia. Literature review, part 3: prescribing errors. Eastern Mediterranean Health Journal, 2011, 17(2):140-148.

28. Goosens $\mathrm{H}$ et al. Outpatient antibiotic use in Europe and association with resistance: a cross-national database study. Lancet, 2005, 365:579-587.

29. Guglielmo L et al. Antimicrobial drug utilization in Italy and other European countries. Infection, 1994, 3:S176- S181.

30. Walley T, Mossialos E. Financial incentives and prescribing. In: Mossialos E, Mrazek M, Walley T, eds. Regulating pharmaceuticals in Europe: striving for efficiency, equity and quality. Milton Keynes, UK, Open University Press, 2004.

31. Jeantaud I, Haramburu F, Begaud B. Consommation de benzodiazepines: enquete aupres de pharmaciens d'officine en aquitaine. [Benzodiazepine consumption: survey of community pharmacies in Aquitaine.] Therapie, 2001, 56:415419.

32. Walley T, Mrazek M, Mossialos E. Regulating Pharmaceutical Markets: improving efficiency and controlling costs in the UK. International Journal of Health Planning and Management, 2005, 20:375-398.

33. Garattini S. Pharmaceutical prescriptions in Italy. International Journal of Technology Assessment in Health Care, 1995, 11:417-427. 
34. Gross FH. Drug utilization data in risk/benefit analyses of drugs-benefit analysis. Acta Medica Scandinavica, 1984, 683:S141-S147.

35. Sunol R, Abello C, Cels IC. Studies in utilization of drugs: a review of different methods. Quality Assurance in Health Care, 1991, 3:63-72.

36. Walley T. Therapeutic conservatism. Journal of the Royal College of Physicians of London, 1994, 28:86-87.

37. Cars O, Molstad S, Melander A. Variation in antibiotic use in the European Union. Lancet, 2001, 357:1851-1853.

38. Walley $\mathrm{T}$ et al. Variations and Increase in use of statins across Europe: data from administrative databases. British Medical Journal, 2004, 328:385-386.

39. Feely J, Barry M. Adverse drug interactions. Clinical Medicine (London, England), 2005, 5:19-22.

40. Walley T et al. Comparison of national administrative and commercial databases to monitor expenditure and costs of statins across Europe. European Journal of Clinical Pharmacology, 2004, 60:503-511.

41. Ibrahim JE, Majoor JW. Quality, adverse events and research International Journal for Quality in Health Care, 2000, 12:357358.

42. McGavock H. Some patterns of prescribing by urban general practitioners. British Medical Journal, 1988, 296:900-902.

43. Majeed A et al. Prescribing of antibiotics and admissions for respiratory tract infections in England. British Medical Journal, 2004, 329:879.

44. Majeed A et al. Prescribing of lipid regulating drugs and admissions for myocardial infarction in England. British Medical Journal, 2004, 329:645.

45. Unsworth L, Walley T. Trends in primary care antibiotic prescribing in England 1994-1998. Pharmacoepidemiology and Drug Safety, 2001, 10:309-314.

46. Wilson $\mathrm{R}$ et al. Influences of practice characteristics on prescribing in fundholding and non-fundholding general practices. British Medical Journal, 1996, 313:595-599.

47. Gill PS, Dowell A, Harris CM. Effect of doctors' ethnicity and country of qualification on prescribing patterns in single handed general practices: linkage of information collected by questionnaire and from routine data. British Medical Journal, 1997, 315:1590-1594.
48. Allery LA, Owen PA, Robling MR. Why general practitioners and consultants change their clinical practice: a critical incident study. British Medical Journal, 1997, 314:870-874.

49. Prosser H, Walley T. Understanding why GPs see pharmaceutical representatives: a qualitative interview study. British Journal of General Practice, 2003, 53:305-311.

50. Sebaie Z, Millier D. BaAgail H. A study of three health centres in rural Saudi Arabia. Saudi Medical Journal, 1980, 1:197-202.

51. Al-Abbassi HM, Madani KA. A survey of outpatient prescriptions dispensed in Saudi Arabia. Australian Journal of Hospital Pharmacy, 1987, 7:211-212.

52. Bawazir SA. Prescribing pattern at community pharmacies in Saudi Arabia. International Pharmacy Journal, 1992, 6:222-224.

53. Al-Dawood K. Evaluation of drug prescribing habits in a postgraduate teaching set-up in Saudi Arabia. Journal of Family and Community Medicine, 1995, 2:41-45.

54. Balbaid OM, Al-Dawood KM. Assessment of physicians' prescribing practices at Ministry of Health hospital in Jeddah city, Saudi Arabia. Saudi Medical Journal, 1998, 19:28-35.

55. Qureshi NA et al. Psychotropic drug prescriptions in primary care and general hospitals, in Saudi Arabia. Saudi Pharmaceutical Journal, 2001, 9:193-200.

56. Al-Ghamdy YS et al. A descriptive study of psychotropic drugs prescriptions in Al-Qassim region, Kingdom of Saudi Arabia. Saudi Pharmaceutical Journal, 1999, 7:44-49.

57. Al-Khaja KA, Al-Ansari TM, Sequeira RP. An evaluation of prescribing errors in primary care in Bahrain. International Journal of Clinical Pharmacology and Therapeutics, 2005, 43:294-301.

58. Moghadamnia AA, Mirbolooki MR, Aghili MB. General practitioner prescribing patterns in Babol city, Islamic Republic of Iran. Eastern Mediterranean Health Journal, 2002, 8:550-555.

59. Otoom $\mathrm{S}$ et al. Evaluation of drug use in Jordan using WHO prescribing indicators. Eastern Mediterranean Health Journal, 2002, 8:537-543.

60. Al-Freihi $\mathrm{H}$ et al. Potential for drug misuse in the eastern province of Saudi Arabia. Annals of Saudi Medicine, 1987, 7:301-305.

61. Al-Faris EA, Al-Taweel A. Audit of prescribing patterns in Saudi primary health care: what lessons can be learned? Annals of Saudi Medicine, 1999, 19:317-321. 